\title{
Covid-19 em Receptores de Transplante de Coração em São Paulo: Uma Série de Casos
}

\author{
Covid-19 in Heart Transplant Recipients in São Paulo: A Case Series
}

Rafaela Vale de Miranda Soriano, ${ }^{1 \oplus}$ João Manoel Rossi Neto, ${ }^{1 \oplus}$ Marco A. Finger, ${ }^{1 \oplus}$ Carolina Casadei Santos $^{1}$

Instituto Dante Pazzanese de Cardiologia, ${ }^{1}$ São Paulo, SP - Brasil

\section{Introdução}

A doença causada pelo novo coronavírus (Covid-19), o SARS-CoV-2 (severe acute respiratory syndrome coronavirus 2), foi declarada uma pandemia pela Organização Mundial da Saúde (OMS) em 11 de março de 2020. ${ }^{1}$ Por analogia a outras infecções respiratórias, principalmente com base na pandemia de 2009 do vírus influenza H1N1,2,3 esperava-se um aumento de casos de pneumonia e progressão para choque séptico com síndrome do desconforto respiratório agudo entre os receptores de transplante de órgão sólido com Covid-19 em comparação com a população não transplantada. ${ }^{4}$ Porém, a imunossupressão no transplante poderia teoricamente revogar a síndrome hiperinflamatória secundária à tempestade de citocinas, responsável pela maioria das mortes pela Covid-19.5,6 Dados sobre a imunossupressão que potencialmente poderiam levar a apresentações clínicas atípicas ou aumentar o risco de eventos adversos na presença de Covid-19 são conflitantes. ${ }^{7,8}$

Relatamos nossa experiência com transplantados de coração (TxC) diagnosticados com Covid-19 em uma instituição com programa de TxC desde 1992 em São Paulo, Brasil.

\section{Material e Métodos}

\section{População e Cenário}

Receptores de TxC adultos atendidos no Instituto Dante Pazzanese de Cardiologia entre março e junho de 2020, com sinais e sintomas sugestivos de infecção por SARSCoV-2 e que testaram positivo para reação em cadeia da

\section{Palavras-chave}

Doenças Cardiovasculares/cirurgia; Transplante do Coração/complicações; Coronavírus; Betacoronavírus; Covid-19; Síndrome Respiratória Aguda; SARS-CoV2; Transplantados; Inflamação.

Correspondência: Rafaela Vale de Miranda Vale de Miranda Soriano • Instituto Dante Pazzanese de Cardiologia - Transplante de Coração Av. Dante Pazzanese, 500. CEP 04012-909, Ambulatório de Transplante de Coração, São Paulo, SP - Brasil

E-mail: rafavaledemiranda@yahoo.com

Artigo recebido em 03/07/2020, revisado em 18/08/2020, aceito em 09/09/2020

DOI: https://doi.org/10.36660/abc.20200722 polimerase com transcriptase reversa (RT-PCR), ou com achados radiológicos compatíveis com Covid-19.

Os dados foram coletados em revisão de prontuários. Foram incluídos história clínica, resultados laboratoriais, marcadores inflamatórios e radiológicos, e terapias administradas. Descrevemos óbito por Covid-19, admissão na Unidade de Terapia Intensiva (UTI), necessidade de ventilação mecânica e disfunção renal.

\section{Métodos Estatísticos}

Os resultados foram relatados de forma descritiva.

\section{Resultados}

Cinco pacientes de TxC foram hospitalizados por Covid-19. Nenhum deles foi diagnosticado por triagem assintomática.

A idade variou de 35 a 79 anos. As comorbidades foram diabetes mellitus (DM) (100\%), hipertensão arterial (HAS) (80\%), doença renal crônica $(40 \%)$ e obesidade (20\%). O tempo de TxC foi de três meses a 264 meses. Foram administrados inibidores da calcineurina em quatro pacientes $(80 \%)$, inibidor da mTOR em $40 \%$, e prednisona e micofenolato em $100 \%$ dos pacientes. Os sintomas foram febre documentada (80\%), tosse na admissão (100\%), dispneia (60\%) e sintomas gastrointestinais (20\%) (Tabela 1$)$.

Conforme Tabela 2, ocorreu linfopenia $\left(<1,500 \mathrm{~mm}^{3}\right)$ em todos os pacientes e trombocitopenia $(<150,000$ $\mathrm{mm}^{3}$ ) em $60 \%$ deles. A troponina estava elevada em um dos casos de óbito, enquanto no outro não foi coletada. Também foi registrada alteração no lactato em um paciente que evoluiu a óbito. Marcadores inflamatórios aumentados foram comuns, sendo mais altos naqueles que necessitaram de cuidados intensivos. Foi realizada tomografia de tórax em todos os pacientes, que apresentaram infiltrados pulmonares bilaterais em vidro fosco. Insuficiência renal esteve presente em $80 \%$.

Conforme descrito na Tabela 3, dois pacientes não receberam terapias empíricas para a Covid-19. Vasopressores e ventilação mecânica foram necessários em $20 \%$ dos pacientes. Nenhum paciente recebeu oxigenação por membrana extracorpórea. Nenhum paciente ficou na posição pronada e o tempo de internação na UTI foi quatro dias para ambos que necessitaram desse cuidado.

Os imunossupressores foram interrompidos em um paciente devido à gravidade do caso. Dois pacientes evoluíram a óbito (40\%), e o restante recebeu alta hospitalar. O tempo de internação variou entre 4 e 21 dias. 
Relato de Caso

\begin{tabular}{lccccccc}
\hline \multicolumn{2}{l}{ Tabela 1 - Dados epidemiológicos e sintomas associados à infecção por SARS-CoV-2 em TxC } & & \\
\hline Pacientes & Idade (anos) & Sexo & $\begin{array}{c}\text { Tempo de transplante } \\
\text { (meses) }\end{array}$ & Comorbidades & Imunossupressão & Sintomas \\
\hline 1 & 79 & Masc. & 264 & HAS, DM, DRC & IC, AM, CE & $\begin{array}{c}\text { Febre, tosse, } \\
\text { dispneia }\end{array}$ \\
\hline 2 & 67 & Masc. & 264 & HAS, DM, DRC & imTOR, AM, CE & Tosse, dispneia \\
\hline 3 & 52 & Fem. & 192 & HAS, DM, Obesidade & IC, AM & Febre, tosse, \\
dispneia
\end{tabular}

Masc: masculino; Fem: feminino; HAS: hipertensão arterial sistêmica; DM: diabetes mellitus; DRC: doença renal crônica; IC: inibidor da calcineurina; imTOR: inibidor da mTOR; AM: antimetabólico; CE: corticoesteroide; SGI: sintomas gastrointestinais.

Tabela 2 - Dados laboratoriais associados à infecção por SARS-CoV-2 em TxC

\begin{tabular}{|c|c|c|c|c|c|c|c|c|c|c|}
\hline Paciente & $\begin{array}{l}\text { Leucócitos } \\
\text { Totais }\left(\mathrm{mm}^{3}\right)\end{array}$ & $\begin{array}{l}\text { Linfócitos } \\
\text { totais }\left(\mathrm{mm}^{3}\right)\end{array}$ & $\begin{array}{c}\text { Plaquetas } \\
<150000 / \mathrm{mm}^{3}\end{array}$ & IRA & $\begin{array}{c}\text { Trop I } \\
\text { (ng/ml) }\end{array}$ & $\begin{array}{l}\text { Dim-D } \\
\text { (mg/L) }\end{array}$ & $\begin{array}{l}\text { Lactato } \\
>2 \mathrm{mmol}\end{array}$ & PCR & $\mathrm{DHL}$ & BNP \\
\hline 1 & 6.100 & 670 & Sim & $\mathrm{Sim}$ & $\mathrm{NC}$ & 1836 & Não & 20 & 397 & $\mathrm{NC}$ \\
\hline 2 & 12.570 & 570 & Sim & Sim & 0.41 & 1.397 & Sim & 40 & 348 & 7.441 \\
\hline 3 & 3.760 & 960 & Não & Não & 0.02 & 287 & Não & 7.1 & 339 & 1.230 \\
\hline 4 & 7.760 & 1.300 & Sim & Sim & 0.01 & $\mathrm{nc}$ & Não & 0.5 & $\mathrm{NC}$ & $\mathrm{NC}$ \\
\hline 5 & 8.350 & 420 & Não & Sim & 0.03 & 675 & Não & 1.1 & $\mathrm{NC}$ & 2.800 \\
\hline
\end{tabular}

IRA: insuficiência renal aguda; Trop: troponina; Dim: dímero; PCR: proteína C-reativa; DHL: Desidrogenase láctica; BNP: Peptídeo natriurético; NC: não coletado.

Tabela 3 - Diagnóstico, terapêutica e desfechos associados à infecção por SARS-CoV-2 em TxC

\begin{tabular}{|c|c|c|c|c|c|c|c|c|}
\hline Pacientes & Diagnóstico & TC de tórax & Óbito & $\begin{array}{c}\text { Tempo de } \\
\text { internação (dias) }\end{array}$ & UTI & DVA & VM & Terapêutica \\
\hline 1 & RT-PCR & $<50 \%$ & Sim & 4 & Sim & Não & Não & Azitromicina, \\
\hline 2 & RT-PCR & $>50 \%$ & $\operatorname{Sim}$ & 4 & Sim & $\operatorname{Sim}$ & Sim & $\mathrm{HCQ}$, Azitromicina, CE \\
\hline 3 & RT-PCR & $<50 \%$ & Não & 11 & Não & Não & Não & NR \\
\hline 4 & TC de tórax & $<50 \%$ & Não & 5 & Não & Não & Não & Azitromicina \\
\hline 5 & RT-PCR & $<50 \%$ & Não & 21 & Não & Não & Não & NR \\
\hline
\end{tabular}

RT-PCR: reação em cadeia da polimerase para SARS-CoV 2; UTI: Unidade de Terapia Intensiva; DVA: droga vasoativa; VM: ventilação mecânica; HCQ: hidroxicloroquina; CE: corticosteroide; NR: não realizado; TC: tomografia computadorizada.

\section{Discussão}

Esta é a primeira descrição de uma série de casos de uma coorte de pacientes transplantados do coração que foram hospitalizados por Covid-19 no Brasil.

Esses pacientes parecem apresentar a Covid19 de forma semelhante a pacientes não transplantados, compartilhando os sintomas mais comuns de febre, tosse e falta de ar. Contrastando com o estudo de Scott, ${ }^{9}$ sintomas gastrointestinais foram observados em apenas um paciente (20\%).

Todos os TxC que foram acometidos pela Covid-19 necessitaram de internação, sendo que o DM estava presente em $100 \%$ deles e HAS em $80 \%$. Na nossa amostra, 40\% dos pacientes necessitaram de cuidados intensivos e tinham o Dímero-D $\geq 1000$ mg/L e PCR $\geq 20$. BNP mostrou-se elevado e DHL não apresentou elevação importante quando medidos. O paciente com troponina elevada apresentou instabilidade hemodinâmica, necessidade de vasopressores e evolução para óbito, o que corrobora a literatura de que lesão miocárdica está associada a piores prognósticos. ${ }^{10}$ Os pacientes que foram para a UTI eram idosos, com tempo de transplante cardíaco maior, e vieram a falecer. Esses dados sugerem uma taxa de mortalidade de transplantados acima da taxa da população geral infectada pela Covid-19. ${ }^{11}$ 


\section{Relato de Caso}

As taxas de linfopenia e trombocitopenia foram mais altas neste estudo quando comparadas com relatos anteriores nas populações não transplantada e transplantada. ${ }^{12,13}$ Este achado poderia ser explicado por uma menor contagem basal de linfócitos e plaquetas devido ao uso de imunossupressores ou representar uma provável interferência adicional da infecção por SARS-CoV-2.

Nosso estudo tem várias limitações comuns aos estudos de TxC: o fato de ter sido realizado em um único centro e o tamanho da nossa amostra, que poderia ser considerado pequeno. Não foi possível tirar conclusões sobre tratamentos específicos para a Covid-19 ou o manejo da imunossupressão nesse cenário. Isso limita nossa compreensão sobre o espectro de sintomas e a gravidade da doença entre TxC com Covid-19.

\section{Conclusão}

Nesta série de casos de pacientes transplantados do coração com Covid-19 atendidos em nossa instituição, a possibilidade teórica de que a imunossupressão poderia revogar a síndrome hiperinflamatória não se mostrou verdadeira. Do ponto de vista observacional, a grande quantidade de fatores de risco e a taxa de mortalidade elevada sugerem que esses receptores poderiam ser particularmente vulneráveis à Covid-19. Estudos maiores e multicêntricos são necessários para confirmar nossos achados.

\section{Referências}

1. Zhu N, Zhang D, Wang W, Li X, Yang B, Song J, et al. A Novel Coronavirus from Patients with Pneumonia in China, 2019. N Engl J Med. 2020 20;382(8):727-33.

2. Cordero E, Pérez-Romero P, Moreno A, Len O, Montejo M, Vidal E, et al. Pandemic influenza $A(H 1 N 1)$ virus infection in solid organ transplant recipients: impact of viral and non-viral co-infection. Clin Microbiol Infect Off Publ Eur Soc Clin Microbiol Infect Dis. 2012 Jan;18(1):67-73.

3. Fernández-Ruiz M, Andrés A, Loinaz C, Delgado JF, López-Medrano F, San Juan R, et al. COVID-19 in solid organ transplant recipients: A single-center case series from Spain. Am J Transplant Off J Am Soc Transplant Am Soc Transpl Surg. 2020;20(7):1849-58.

4. Zhu L, Gong N, Liu B, Lu X, Chen D, Chen S, et al. Coronavirus Disease 2019 Pneumonia in Immunosuppressed Renal Transplant Recipients: A Summary of 10 Confirmed Cases in Wuhan, China. Eur Urol. 2020;77(6):748-54.

5. Mehta P, McAuley DF, Brown M, Sanchez E, Tattersall RS, Manson JJ, et al. COVID-19: consider cytokine storm syndromes and immunosuppression. Lancet Lond Engl. 2020 28;395(10229):1033-4.

6. Kumar D, Manuel O, Natori Y, Egawa H, Grossi P, Han S, et al. COVID-19: A global transplant perspective on successfully navigating a pandemic. Am J Transplant .2020;20(7):1773-9.'

\section{Contribuição dos autores}

Concepção e desenho da pesquisa: Soriano RVM, Rossi Neto JM, Finger MA, Santos CC; Obtenção de dados: Soriano RVM; Análise e interpretação dos dados e Revisão crítica do manuscrito quanto ao conteúdo intelectual importante: Rossi Neto JM, Finger MA, Santos CC; Análise estatística: Rossi Neto JM; Redação do manuscrito: Soriano RVM, Rossi Neto JM.

\section{Potencial conflito de interesses}

Declaro não haver conflito de interesses pertinentes.

\section{Fontes de financiamento}

O presente estudo não teve fontes de financiamento externas.

\section{Vinculação acadêmica}

Não há vinculação deste estudo a programas de pósgraduação.

\section{Aprovação ética e consentimento informado}

Este artigo não contém estudos com humanos ou animais realizados por nenhum dos autores.

7. Zhang H, Dai H, Xie X. Solid Organ Transplantation During the COVID-19 Pandemic. Front Immunol .2020;11:1392.

8. Yi SG, Rogers AW, Saharia A, Aoun M, Faour R, Abdelrahim M, et al. Early Experience With COVID-19 and Solid Organ Transplantation at a US Highvolume Transplant Center. Transplantation.2020;104(11):2208-14..

9. Ketcham SW, Adie SK, Malliett A, Abdul-Aziz AA, Bitar A, Grafton G, et al. Coronavirus Disease-2019 in Heart Transplant Recipients in Southeastern Michigan: A Case Series. J Card Fail. 2020 .26(6):457-61.

10. Shi S, Qin M, Shen B, Cai Y, Liu T, Yang F, et al. Association of Cardiac Injury With Mortality in Hospitalized Patients With COVID-19 in Wuhan, China. JAMA Cardiol. 2020 5(7):802-10.

11. Wilson N, Kvalsvig A, Barnard LT, Baker MG. Case-Fatality Risk Estimates for COVID-19 Calculated by Using a Lag Time for Fatality. Emerg Infect Dis. 2020 Jun;26(6):1339-441.

12. Huang D, Lian X, Song F, Ma H, Lian Z, Liang Y, et al. Clinical features of severe patients infected with 2019 novel coronavirus: a systematic review and meta-analysis. Ann Transl Med. 2020 May;8(9):576.

13. Akalin E, Azzi Y, Bartash R, Seethamraju H, Parides M, Hemmige V, et al. Covid-19 and Kidney Transplantation. N Engl J Med. 2020 $18 ; 382(25): 2475-7$ 